Tropical Journal of Pharmaceutical Research September 2021; 20 (9): 1991-1997

ISSN: $1596-5996$ (print); 1596-9827 (electronic)

(C) Pharmacotherapy Group, Faculty of Pharmacy, University of Benin, Benin City, 300001 Nigeria.

Original Research Article

http://dx.doi.org/10.4314/tjpr.v20i9.28

\title{
Therapeutic effect of Xuezhitong capsule on microvascular angina
}

\author{
Xiaomei Ma1, Dehui Yang ${ }^{2}$, Weichun Shen ${ }^{3}$, Wei Liang ${ }^{2}$, Qian Lin ${ }^{4 *}$ \\ ${ }^{1}$ Traditional Chinese Medicine Department, Beijing City Fengtai District Nanyuan Hospital, Beijing, ${ }^{2}$ Changchun University of \\ Chinese Medicine, Changchun City, ${ }^{3}$ Beijing Huashi Kangyuan Pharmaceutical Technology Co. Ltd, ${ }^{4}$ Department of Cardiology, \\ Dongzhimen Hospital Beijing University of Chinese Medicine, Beijing, China
}

*For correspondence: Email: niduizhan017358749@163.com

Sent for review: 6 June 2021

Revised accepted: 20 August 2021

\begin{abstract}
Purpose: To determine the therapeutic effect of Xuezhitong capsule in patients with microvascular angina (MVA), and its impact on vascular endothelial function.

Methods: In total, 172 MVA patients treated in Beijing City Fengtai District Nanyuan Hospital from September 2017 to September 2019 were selected and randomized into control group which received conventional treatment, and treatment group which received Xuezhitong capsules plus. There were 86 patients in each group. Therapeutic effect, levels of inflammatory factors, i.e., high-sensitivity C-reactive protein (hs-CRP), interleukin-(IL-6), tumor necrosis factor- $\alpha$ (TNF- $\alpha$ ), and vascular endothelial factors such as nitric oxide (NO), thromboxane B2 (TXB2) and endothelin (ET), were determined.

Results: Markedly higher total treatment effectiveness was observed in the treatment group than in the control group (89.53 \% vs. $72.94 \% ; p<0.05)$. In both groups, treatment reduced the levels of hs-CRP, IL-6, TNF- $\alpha$, TXB2 and ET, but elevated NO, with better results for treatment group than the control group ( $p<0.05)$. Better optimizations of total cholesterol (TC), triglycerides (TGs), low-density lipoprotein cholesterol (LDL-C) and high-density lipoprotein (HDL) were observed in the treatment group, relative to the control group $(p<0.05)$. Patients in the treatment group experienced fewer $(8.14$ $\%)$ adverse reactions than those in control group $(21.18 \%, p<0.05)$.

Conclusion: Xuezhitong capsule, when combined with conventional treatment, exerts high therapeutic effectiveness and safety in MVA patients by inhibiting inflammatory reactions, optimizing endothelial function, reducing blood lipid levels, and decreasing the incidence of cardiovascular adverse events. Thus, the combination therapy is a potentially superior therapeutic strategy to the conventional approach for the management of MVA patients.
\end{abstract}

Keywords: Xuezhitong capsule, MVA, Vascular endothelial function, Inflammatory factors, Blood lipids

This is an Open Access article that uses a funding model which does not charge readers or their institutions for access and distributed under the terms of the Creative Commons Attribution License (http://creativecommons.org/licenses/by/4.0) and the Budapest Open Access Initiative (http://www.budapestopenaccessinitiative.org/read), which permit unrestricted use, distribution, and reproduction in any medium, provided the original work is properly credited.

Tropical Journal of Pharmaceutical Research is indexed by Science Citation Index (SciSearch), Scopus, International Pharmaceutical Abstract, Chemical Abstracts, Embase, Index Copernicus, EBSCO, African Index Medicus, JournalSeek, Journal Citation Reports/Science Edition, Directory of Open Access Journals (DOAJ), African Journal Online, Bioline International, Open-J-Gate and Pharmacy Abstracts

\section{INTRODUCTION}

Microvascular angina (MVA), also known as cardiac $\mathrm{X}$ syndrome (CXS), is characterized by fatigue-triggered angina, positive exercise electrocardiogram (ECG), normal coronary angiography, and negative ergonovine test, all of which result in diagnostic conundrum in differentiating MVA from stable angina [1,2]. Microvascular angina (MVA) is a common 
cardiovascular disease diagnosed at an increasing rate due to the popularity of coronary angiography [3]. It manifests as a coronary microvascular circulatory disorder without obstructive coronary artery disease, and it has been proposed that its pathogenesis is basically associated with dyslipidemia and vascular endothelial dysfunction that may trigger a cascade of cardiovascular diseases and overexpression of inflammatory factors [4,6]. Consequently, it is of great significance to the prevention of MVA to control blood lipids, protect vascular endothelial function and abate inflammation response [7]. In the etiological and pathological theory of traditional Chinese medicine (TCM), MVA is categorized as "chest impediment and heart pain disease". Xuezhitong capsule is effective in regulating yang and $q i$, resolving phlegm and dissipating mass, activating blood circulation and removing stasis. Moreover, it reduces blood lipids and exerts dual regulatory effects on peripheral blood vessels, thereby playing a crucial role in the treatment of chest and heart pain due to mutual obstruction of phlegm and blood stasis [8]. Xuezhitong capsule is employed in our hospital for effective treatment of MVA patients.

\section{METHODS}

\section{Patients}

We selected 172 MVA patients from September 2017 to September 2019 randomly assigned them equally to a treatment group and a control group using the random number table method. There were 85 patients in the control group (1 patient dropped out), comprising 26 females and 16 males, aged $43-74$ years (mean age $=59.1$ \pm 6.2 years), with disease duration of $2-10$ years (mean duration $=4.1 \pm 1.2$ years). There were 86 patients in the treatment group, comprising 23 females and 20 males, aged 41 . 73 years (mean age $=60.2 \pm 6.2$ years), and disease duration of 2 - 9 years (mean duration = $4.2 \pm 1.3$ years). The general data were comparable between the two groups $(p>0.05)$. Ethical approval for the human studies was obtained from the Ethics Committee of Beijing City Fengtai District Nanyuan Hospital (approval no. 2016-CE/332), and followed international guidelines for human studies [9].

\section{Inclusion and exclusion criteria}

\section{Inclusion criteria}

The following categories of patients were included: (1) Patients diagnosed as MVA using physical examination, medical history, and laboratory examinations, and who met the diagnostic criteria of chest impediment and heart pain with mutual obstruction of phlegm and blood stasis in line with the Principles of Clinical Research Indices for New Traditional Chinese Medicines [10]; (2) male and female patients aged between 40 and 80 years old; (3) patients without any allergies or resistance to the study drugs; (4) those who had no serious organ diseases such as diabetes, liver disease, kidney disease, and other systemic diseases; and (5) patients who were aware of the purpose of this study, and voluntarily participated and signed informed consent form.

\section{Exclusion criteria}

(1) Patients with abnormal results in echocardiography and X-ray examination; (2) patients with impaired consciousness, language disorder or mental abnormality; (3) those who dropped out of the study and those who did not cooperate in the study, and (4) pregnant or breast-feeding patients.

\section{Treatments}

The control group received conventional treatment for coronary heart disease, such as nitrate drugs, anti-platelet drugs, lipid-regulating and plaque-stabilizing drugs, angiotensinconverting enzyme inhibitors, and $\beta$-receptor blockers.

The treatment group was treated with Xuezhitong capsules (Jilin Dongfang Pharmaceutical Co. Ltd., National Medical Products Administration of China (approval no. Z10970076), $0.45 \mathrm{~g} /$ capsule, at a dose of 2 capsules 3 times/day plus. Both groups were treated for 8 weeks and followed up for 6 months.

\section{Assessment of therapeutic indices}

\section{Clinical efficacy}

Based on the number of episodes of angina, clinical efficacy was divided into markedly effective, effective and ineffective. A reduction $>80 \%$ in the number of angina episodes was considered markedly effective; 50 to $80 \%$ reductions were considered effective, while reductions $\leq 50 \%$ were ineffective.

Total treatment effectiveness was calculated as shown in Eq 1. TRT $(\%)=\{(\mathrm{Ns}+\mathrm{Ne}) / \mathrm{Nt}\} 100 \%$, where TRT $(\%)=$ Total effectiveness, Ns = no. of significantly effective cases, $\mathrm{Ne}=$ no. of effective cases, and $\mathrm{Nt}=$ total no. of cases.

Trop J Pharm Res, September 2021; 20(9): 1992 


\section{Frequency and duration of angina}

The frequency and duration of angina before treatment and 12 weeks after treatment were monitored and recorded.

Inflammatory factor levels, endothelial function indices and blood lipid indices

Fasting venous blood was drawn from the patients on the day after admission and 12 weeks after treatment. Concentrations of plasma hs-CRP, IL-6 and TNF- $\alpha$ were determined with enzyme-linked immunosorbent assay. Radioimmunoassay was used to determine plasma levels of NO, TXB2 and ET, while an automatic biochemical analyzer was used to determine plasma concentrations of TC, TGs, LDL-C and HDL.

Incidence of adverse reactions: The two groups of patients were followed up for 6 months after treatment. Gastrointestinal reactions, dizziness, abnormal liver and kidney function, and other adverse reactions were determined and recorded, and the incidence of adverse reactions was determined.

\section{Statistical analysis}

Measurement data and count data are presented as mean \pm standard deviation (SD), and number and percentages [n, (\%)], respectively. Statistical analyses were done with $t$-test and chi-square test using SPSS ver 20.0. Values of $p<0.05$ indicated that differences were statistically significant.

\section{RESULTS}

\section{Clinical efficacy}

Table 1 shows higher total effectiveness of $89.53 \%(77 / 86)$ in the treatment group than in the control group [72.94\% $(62 / 85 ; p<0.05)]$.

\section{Frequency and duration of angina}

Before treatment, the frequencies of angina in the experimental and control groups were $6.78 \pm$ 1.73 and $7.01 \pm 2.46$ times/week, and the angina durations were $5.67 \pm 1.30$ and $5.88 \pm 1.59$ ) min/time, respectively. No significant differences in these parameters were observed between the groups. However, after treatment, there were evident decreases in these two indicators, with a lower angina frequency of $1.56 \pm 0.45$ times/week, and shorter angina duration of 1.35 $\pm 0.42 \mathrm{~min} /$ time in the treatment group than the responding values of $2.37 \pm 0.53$ times/week and $2.05 \pm 0.36 \mathrm{~min} /$ time in the control group $(p<$ $0.05)$. These results are shown in Figure 1 and Figure 2.

\section{Levels of inflammatory factors}

There were no statistical differences in levels of hs-CRP, IL-6 and TNF- $\alpha$ in the two groups before treatment. However, the levels of these inflammatory factors plummeted after treatment, with lower values in the treatment group than in the control group. These results are shown in Table 2.

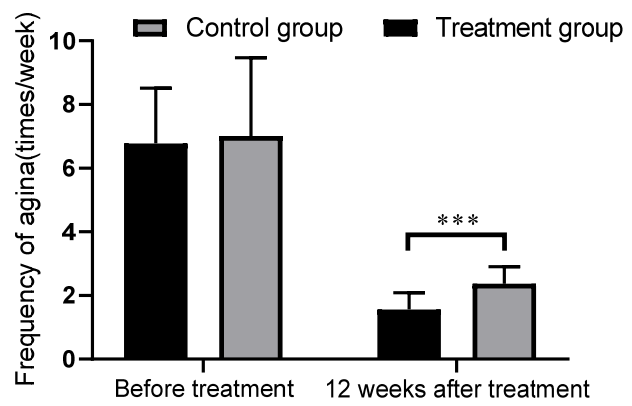

Figure 1: Comparison of the frequency of angina

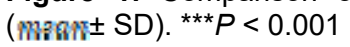

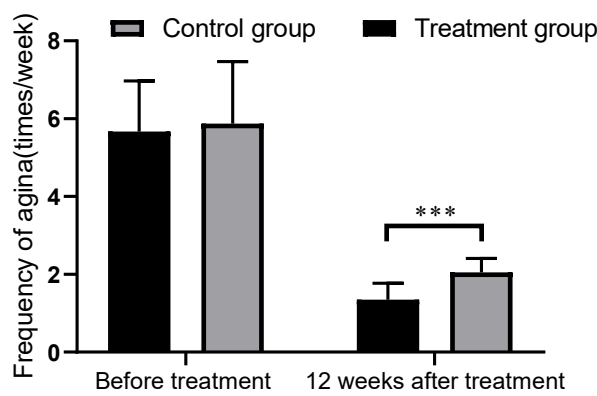

Figure 2: Comparison of the duration of angina

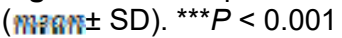

Table 1: Comparison of clinical effectiveness [n (\%)]

\begin{tabular}{lcccc}
\hline Group & Markedly effective & Effective & Ineffective & Total effectiveness \\
\hline Treatment group $(\mathrm{n}=86)$ & $56(65.12)$ & $21(24.42)$ & $9(27.06)$ & $77(89.53)$ \\
Control group $(\mathrm{n}=85)$ & $44(57.16)$ & $18(21.18)$ & $23(27.06)$ & $62(72.94)$ \\
$X^{2}$ & & & & 7.738 \\
$P$-value & & & 0.005 \\
\hline
\end{tabular}


Table 2: Comparison of the levels of inflammatory factors (ment SD)

\begin{tabular}{lcccccc}
\hline Group & \multicolumn{2}{c}{ hs-CRP (mg/L) } & \multicolumn{2}{c}{ IL-6 (ng/L) } & \multicolumn{2}{c}{ TNF- $\alpha(\mathbf{n g} / \mathbf{L})$} \\
\cline { 2 - 7 } & $\begin{array}{c}\text { Before } \\
\text { treatment }\end{array}$ & $\begin{array}{c}\text { After } \\
\text { treatment }\end{array}$ & $\begin{array}{c}\text { Before } \\
\text { treatment }\end{array}$ & $\begin{array}{c}\text { After } \\
\text { treatment }\end{array}$ & $\begin{array}{c}\text { Before } \\
\text { treatment }\end{array}$ & $\begin{array}{c}\text { After } \\
\text { treatment }\end{array}$ \\
\hline $\begin{array}{c}\text { Treatment } \\
(\mathrm{n}=86)\end{array}$ & $13.90 \pm 4.72$ & $5.72 \pm 1.77$ & $144.35 \pm 23.45$ & $62.35 \pm 11.24$ & $33.25 \pm 8.21$ & $15.68 \pm 3.68$ \\
Control & & & & & & \\
$(\mathrm{n}=85)$ & $13.18 \pm 3.47$ & $7.63 \pm 4.19$ & $148.22 \pm 28.83$ & $82.19 \pm 17.33$ & $34.08 \pm 7.93$ & $20.46 \pm 2.85$ \\
$\mathrm{~T}$ & 1.135 & 3.891 & 0.964 & & & \\
$P$-value & 0.258 & $<0.001$ & 0.337 & $<0.001$ & 0.672 & 9.489 \\
\hline
\end{tabular}

Table 3: Comparison of vascular endothelial function indices (mentw $\pm S D$ )

\begin{tabular}{lcccccc}
\hline Group & \multicolumn{2}{c}{ NO $(\mathbf{m g} / \mathrm{L})$} & \multicolumn{2}{c}{ TXB2 $(\mathbf{n g} / \mathrm{L})$} & \multicolumn{2}{c}{ ET (ng/L) } \\
\cline { 2 - 7 } & $\begin{array}{c}\text { Before } \\
\text { treatment }\end{array}$ & $\begin{array}{c}\text { After } \\
\text { treatment }\end{array}$ & $\begin{array}{c}\text { Before } \\
\text { treatment }\end{array}$ & $\begin{array}{c}\text { After } \\
\text { treatmentG }\end{array}$ & $\begin{array}{c}\text { Before } \\
\text { treatment }\end{array}$ & $\begin{array}{c}\text { After } \\
\text { treatment }\end{array}$ \\
\hline $\begin{array}{c}\text { Treatment } \\
(\mathrm{n}=86)\end{array}$ & $63.27 \pm 12.46$ & $82.15 \pm 22.03$ & $122.08 \pm 20.14$ & $78.24 \pm 13.57$ & $73.26 \pm 12.46$ & $44.83 \pm 9.24$ \\
$\begin{array}{l}\text { Control } \\
(\mathrm{n}=85)\end{array}$ & $65.92 \pm 14.29$ & $71.13 \pm 17.57$ & $124.62 \pm 18.58$ & $91.67 \pm 20.14$ & $75.02 \pm 14.57$ & $58.67 \pm 10.26$ \\
$T$ & 1.293 & 3.614 & 0.857 & & & \\
$P$-value & 0.198 & $<0.001$ & 0.393 & $<0.119$ & 0.849 & 9.271 \\
\hline
\end{tabular}

\section{Vascular endothelial function indices}

Table 3 shows that before treatment, there were no marked differences in vascular endothelial function indices such as NO, TXB2 and ET between the two groups. However, after treatment, both groups had apparent elevation of NO levels and decreased levels of TXB2 and ET, with the treatment group having a superior result, relative to the control group $(p<0.05)$.

\section{Blood lipid indices}

As displayed in Figures 3-6, no statistically significant differences in blood lipid indices were seen between the two groups before treatment. After treatment, there were significant decreases in HDL in the two groups of patients, while TC, TG, and LDL-C were markedly increased, with the treatment group having a better profile than the control group $(p<0.05)$.

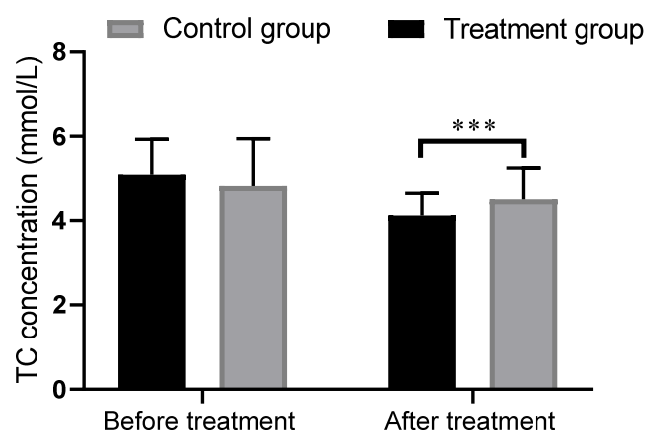

Figure 3: Comparison of plasma TC concentration (moni⿱亠 SD). ${ }^{* *} P<0.001$

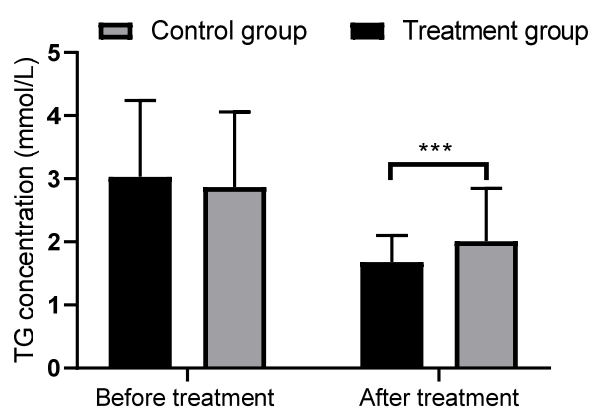

Figure 4: Comparison of plasma TG concentrations (monพ \pm SD). ${ }^{* * *} P<0.001$

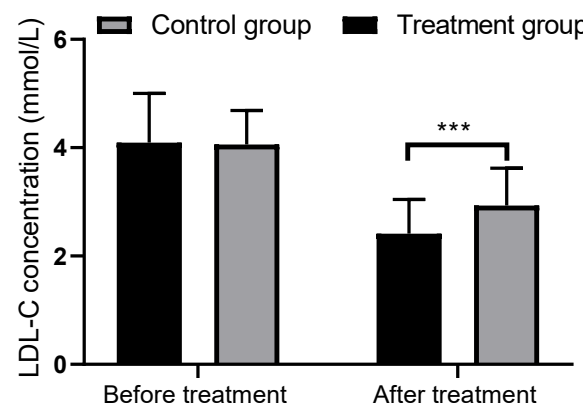

Figure 5: Comparison of plasma LDL-C concentration (monit SD). ${ }^{* * *} P<0.001$

\section{Incidence of adverse reactions}

Patients in the treatment group had a lower incidence of adverse reactions $(8.14 \% ; 7 / 86)$ than those in the control group $(21.18 \% ; 18 / 85)$ $(p<0.05)$. These results are shown in Table 4. 
Table 4: Comparison of the incidence of adverse reactions [n (\%)]

\begin{tabular}{lccccc}
\hline Group & $\begin{array}{c}\text { Gastrointestinal } \\
\text { reaction }\end{array}$ & Dizziness & $\begin{array}{c}\text { Abnormal liver and } \\
\text { kidney function }\end{array}$ & Other & $\begin{array}{c}\text { Adverse } \\
\text { reaction rate }\end{array}$ \\
\hline $\begin{array}{l}\text { Treatment } \\
(\mathrm{n}=86)\end{array}$ & $3(3.49)$ & $1(1.16)$ & $1(1.16)$ & $(2.33)$ & $7(8.14)$ \\
Control $(\mathrm{n}=85)$ & $5(5.88)$ & $4(4.71)$ & $3(3.53)$ & 6 & $18(21.18)$ \\
$\mathrm{X} 2$ & & & & $(7.06)$ & 5.821 \\
$P$-value & & & & & 0.016 \\
\hline
\end{tabular}

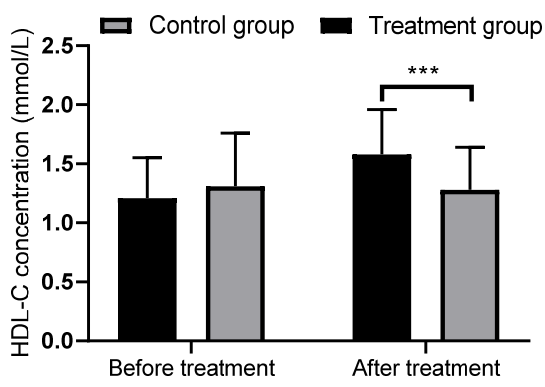

Figure 6: Comparison of plasma HDL-C concentration (meañ SD). ${ }^{* * *} P<0.001$

\section{DISCUSSION}

Microvascular angina (MVA) refers to clinical syndromes consistent with quintessential fatiguetriggered angina, positive exercise ECG, normal left ventricular function as diagnosed using Doppler echocardiography, and normal coronary angiography, but without chest pain due to coronary artery spasm [11]. Studies have shown that ischemic heart disease may be triggered by a series of pathological changes such as vascular endothelial damage, smooth muscle proliferation, ischemia-induced platelet aggregation, high blood lipids, and atherosclerotic plaque [12].

Long-term endothelial dysfunction and dyslipidemia lead to the thickening of blood vessel walls and narrowing of the lumen, which further exacerbate ischemia. Therefore, optimization of vascular endothelial function and blood lipids are key to the treatment of ischemic heart disease [13]. Although Western medicine is effective in the treatment of non-microvascular disease, it is does not yield a satisfactory therapeutic effect in the treatment of MVA. This is as a consequence of the absence of largesample random clinical trial reports, and the adoption of conservative conventional treatment strategies such as improvement of lifestyle, prevention of complications, regulation of lipids and stabilization of plaques, employment of angiotensin-converting enzyme inhibitors, and optimization of myocardial ischemia [14].
In TCM, MVA is categorized as "chest impediment and heart pain" disease, with most common symptoms of phlegm obstruction, blood stasis, and yang deficiency [15]. The conditions of all the patients in this study conformed with "mutual obstruction of phlegm and blood stasis", with specific pathogenesis of internal obstruction by phlegm-dampness, which blocks the movement of $q i$ and triggers blood stasis, resulting chest impediment and heart pain. Xuezhitong capsule is a medicine made from the Chinese medicine herb Xiebai which has been recorded in "Compendium of Materia Medica" with an efficacy to "treat chest pain and disperse qi and blood". Similarly, in the prescription from the Chinese medical sage Zhang Zhongjing, Gualou Xiebai Banxia Decoction and Gualou Xiebai Baijiu Decoction were also employed for treating chest impediment and heart pain.

Studies have shown that Xiebai, which relieves chest pain and regulates qi, promotes blood circulation and removes blood stasis, exerts these pharmacological effects on cardiovascular disease by reducing blood lipids, abating atherosclerosis, and inhibiting platelet aggregation [17]. Moreover, studies have demonstrated that Xiebai contains a variety of effective bioactive compounds including 19 types of volatile sulfur components such as methallyl trisulfide, scallion A-L, scallion and adenosine, [18]. With volatile sulfur as the main bioactive component, Xuezhitong capsule produces beneficial effects by lowering blood lipids, inhibiting platelet aggregation, abating thrombosis, and preventing atherosclerosis. The involvement of inflammatory response in all stages of the occurrence and development of coronary heart disease is indicative of the importance of its mitigation in the treatment of MVA [19]. Correspondingly, the results of this study showed that levels of hs-CRP, IL- 6 and TNF- $\alpha$ in the treatment group were significantly lower than those in the control group, thereby confirming the effect of Xuezhitong capsule in the mitigation of inflammation response. However, the mechanism involved in this process requires further investigations. Studies have revealed that $\mathrm{NO}$ is able to increase calcium ion permeability, promote vasodilation, abate platelet aggregation, 
and prevent thrombosis, while ET-1 effectively relaxes vascular smooth muscle and blood vessels, and TXB2 induces platelet aggregation and promotes thrombosis [20]. There were no significant differences in vascular endothelial function indices such as NO, TXB2 and ET between the two groups of patients before treatment. However, after treatment, the two groups had raised NO levels, while levels of TXB2 and ET were reduced, with the treatment group having a better result, indicating that the Xuezhitong capsule mitigated vascular endothelial function. Pharmacological studies have revealed that Xuezhitong capsules promote the synthesis and release of $\mathrm{NO}$, and decrease the levels of TXB2 and ET, which are consistent with the results of this study. The effect of the Xuezhitong capsule in improving blood lipid profiles has been recognized and further confirmed in this study in which there were observably better profiles of TC, TGs, LDL-C and $\mathrm{HDL}$ in the treatment group than in the control group. Furthermore, the apparently lower incidence of adverse reactions in the treatment group is an indication of the safety of the capsule.

\section{CONCLUSION}

The combination of Xuezhitong capsule and conventional treatment produces good therapeutic effect and safety in MVA patients by inhibiting inflammatory reactions, optimizing endothelial function, reducing blood lipid levels, and bringing down the incidence of cardiovascular adverse events. Thus, this therapeutic strategy is recommended for the management of MVA patients.

\section{DECLARATIONS}

\section{Conflict of interest}

No conflict of interest is associated with this work.

\section{Contribution of authors}

We declare that this work was done by the authors named in this article and all liabilities pertaining to claims relating to the content of this article will be borne by the authors.

\section{Open Access}

This is an Open Access article that uses a funding model which does not charge readers or their institutions for access and distributed under the terms of the Creative Commons Attribution
License (http://creativecommons.org/licenses/by/ 4.0) and the Budapest Open Access Initiative (http://www.budapestopenaccessinitiative.org/rea d), which permit unrestricted use, distribution, and reproduction in any medium, provided the original work is properly credited.

\section{REFERENCES}

1. Titterington JS, Hung OY, Wenger NK. Microvascular angina: an update on diagnosis and treatment. Future Cardiol 2015; 11(2): 229-242.

2. Lee BK, Lim HS, Fearon WF, Yong AS, Yamada $R$, Tanaka S, Lee DP, Yeung AC, Tremmel JA. Invasive evaluation of patients with angina in the absence of obstructive coronary artery disease. Circulation 2015; 131(12): 1054-1060.

3. Liu A, Wijesurendra RS, Liu JM, Forfar JC, Channon KM, Jerosch-Herold M, Piechnik SK, Neubauer S, Kharbanda RK, Ferreira VM. Diagnosis of Microvascular Angina Using Cardiac Magnetic Resonance. J Am Coll Cardiol 2018; 71(9): 969-979.

4. Suzuki H. Different definition of microvascular angina. Eur J Clin Invest 2015; 45(12): 1360-6.

5. Kaski JC, Crea F, Gersh BJ, Camici PG. Reappraisal of Ischemic Heart Disease. Circulation. 2018; 138: 14631480.

6. Tselepis $A D$, Elisaf $M$, Goudevenos $J$, Tselegaridis $T$, Bairaktari E, Siamopoulos KC, Sideris D. Lipid profile in patients with microvascular angina. Eur J Clin Invest 1996; 26(12): 1150-5.

7. Goto M. Exploring Deep Into the Coronary Microcirculation of Patients With Microvascular Angina. Circ J 2018; 82(4): 951-953.

8. Zhou W, Wang Y. A network-based analysis of the types of coronary artery disease from traditional Chinese medicine perspective: potential for therapeutics and drug discovery. J Ethnopharmacol 2014; 151(1): 66-77.

9. Department of Health, Education, and Welfare; National Commission for the Protection of Human Subjects of Biomedical and Behavioral Research. The Belmont Report. Ethical principles and guidelines for the protection of human subjects of research. J Am Coll Dent 2014; 81(3): 4-13.

10. Wang WJ, Zhang T. Integration of traditional Chinese medicine and Western medicine in the era of precision medicine. J Integr Med 2017; 15(1): 1-7.

11. Ford TJ, Rocchiccioli P, Good R, McEntegart M, Eteiba $H$, Watkins S, Shaukat A, Lindsay M, Robertson $K$, Hood $S$, et al. Systemic microvascular dysfunction in microvascular and vasospastic angina. Eur Heart $J$ 2018; 39(46): 4086-4097.

12. Shah SJ, Borlaug BA, Kitzman DW, McCulloch $A D$, Blaxall BC, Agarwal R, Chirinos JA, Collins S, Deo RC, Gladwin MT, et al. Research Priorities for Heart Failure With Preserved Ejection Fraction: National Heart, Lung, and Blood Institute Working Group Summary. Circulation 2020; 141(12): 1001-1026.

Trop J Pharm Res, September 2021; 20(9): 1996 
13. Chen C, Wei J, AlBadri A, Zarrini P, Bairey Merz CN. Coronary Microvascular Dysfunction- Epidemiology, Pathogenesis, Prognosis, Diagnosis, Risk Factors and Therapy. Circ J 2016; 81(1): 3-11.

14. Crea F, Lanza GA. Treatment of microvascular angina: the need for precision medicine. Eur Heart $J$ 2016; 37(19): 1514-6.

15. Zhong L, Zhuang J, Jin Z, Chen Y, Chen B. Effect of Chinese medicine for promoting blood circulation on microvascular angina: A systematic review and metaanalysis. Am J Emerg Med 2020; 38(12): 2681-2692.

16. Zheng J, Xiao $T$, Ye $P$, Miao D, Wu H. Xuezhikang reduced arterial stiffness in patients with essential hypertension: a preliminary study. Braz J Med Biol Res 2017; 50(10): e6363.

17. Chen M, Men L, Wu H, Zhong G, Ou L, Li T, Guo Y, Lin $H$, Zhang J, Wang $D$, et al. A systematic review of the effectiveness and safety of Chinese herbal medicine formula Gualou Xiebai Banxia (GLXBBX) decoction for the treatment of stable angina pectoris. Medicine (Baltimore) 2019; 98(51): e18375.

18. Lin P, Qin Z, Yao Z, Wang L, Zhang W, Yu Y, Dai Y, Zhou H, Yao X. Metabolites profile of Gualou Xiebai Baijiu decoction (a classical traditional Chinese medicine prescription) in rats by ultra-performance liquid chromatography coupled with quadrupole time-of-flight tandem mass spectrometry. J Chromatogr B Analyt Technol Biomed Life Sci 2018; 1085: 72-88.

19. Wu T, Harrison RA, Chen X, Ni J, Zhou L, Qiao J, Wang $Q$, Wei J, Xin D, Zheng J. Tongxinluo (Tong xin luo or Tong-xin-luo) capsule for unstable angina pectoris. Cochrane Database Syst Rev 2006; 18(4): CD004474.

20. Chen Z, Hu L, Liao Y, Zhang X, Yang Z, Hu C, Yu L. Different Processed Products of Curcumae Radix Regulate Pain-Related Substances in a Rat Model of Qi Stagnation and Blood Stasis. Front Pharmacol 2020; 11: 242. 